Portland State University

PDXScholar

1982

\title{
A study of age and sex-related differences in the perception of emotional stimuli
}

Nancy Mellor Canizio

Portland State University

Follow this and additional works at: https://pdxscholar.library.pdx.edu/open_access_etds

Part of the Cognition and Perception Commons, and the Social Psychology Commons Let us know how access to this document benefits you.

\section{Recommended Citation}

Canizio, Nancy Mellor, "A study of age and sex-related differences in the perception of emotional stimuli" (1982). Dissertations and Theses. Paper 3153.

https://doi.org/10.15760/etd.3142

This Thesis is brought to you for free and open access. It has been accepted for inclusion in Dissertations and Theses by an authorized administrator of PDXScholar. Please contact us if we can make this document more accessible: pdxscholar@pdx.edu. 
AN ABSTRACT OF THE THESIS OF Nancy Mellor Canizio

for the Master of Science in Psychology presented August 12, 1982.

A Study of Age and Sex-related Differences in the Perception of Emotional Stimuli

APPROVED BY MEMBERS OF THE THESIS COMMITTEE:

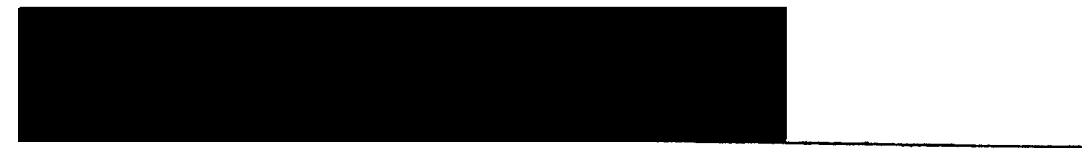

Dr. James Pautson, Chairman

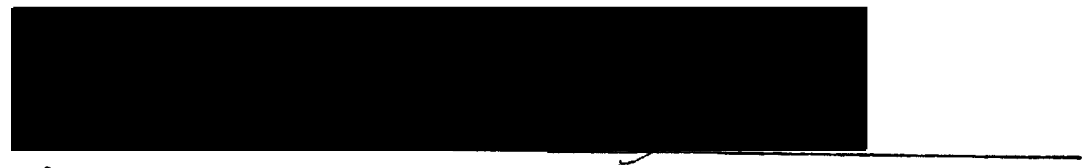

Dr. Gerald Murch

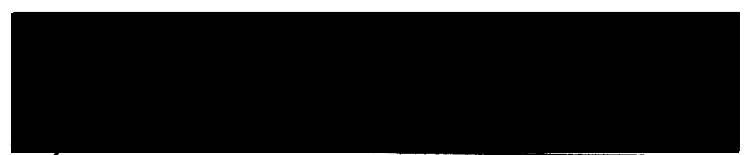

Dr. Gerald Guthrie

In a tachistoscopic perception task, adult males in the Fels Research Institute's longitudinal population (Kagan and Moss, 1960) were found to have a higher recognition threshold for pictures depicting dependency scenes than adult females. The female subjects had a higher recognition threshold for aggressive scenes than the males.

The present study was designed to further compare male and female perception of dependent and aggressive stimuli by including a developmental component to test if the perceptual differences vary with age. A benign or neutral stimulus category was added to aid in determining direction of any resulting differences: 
i.e., heightened perception or avoidance of perception, and a recognition memory task was added to the tachistoscopic task to determine if there were any differences between sensory and long term memory of emotional stimuli.

A pretest was administered each subject in four age groups to establish individual visual thresholds in the tachistoscope. Preschoolers, third graders, ninth graders and college students were then tested on a matching procedure at threshold level (sensory memory task), and 48 hours later, above threshold, on a recognition memory task. The stimuli were colored photographs depicting aggressive, dependent and benign interactions of two adults, and the dependent measure was the number of correct identifications in each stimulus category: aggressive, dependent, and benign. Age by sex analyses of variance were calculated on three variables abstracted from the correct responses of the subjects to the three categories of stimuli. The variables were 1) overall number of correct identifications, 2) number of correct identifications of dependent photographs minus the number of correct identifications of aggressive photographs, and 3) the mean number of correct identifications of emotional photographs (aggressive and dependent) minus the number of correct identifications of benign photographs. The overal1, dependent/aggressive and emotional/benign comparisons were analyzed on both the sensory memory and recognition memory tasks.

Significant differences were found in the aggressive/dependent comparison on both tasks, and in the emotional/benign comparison on the sensory memory task. Ninth grade males and females accurately 
identified comparatively more dependent than aggressive pictures than the other three age groups on the sensory memory task. On the recognition memory task; ninth grade males and females accurately identified more aggressive than dependent pictures. There was a significant age by sex interaction on the emotional/benign comparison. Preschool males accurately identified comparatively more emotional than benign pictures, and college males accurately identified comparatively more benign than emotional. The results were reversed among females, with preschool females identifying more benign than emotional pictures and college females identifying more emotional than benign. There was comparatively little difference between males and females at the third grade and ninth grade levels.

Thus, the results of Kagan and Moss (1960) were not substantiated. Rather than a sex difference in the perception of dependency and aggression, there was an age difference which depends on whether the memory process being tested is sensory or long term. Biological and sociological changes appear to be accelerated in the adolescent phase, and both factors could be expected to affect perception. The age by sex interaction on the emotional/benign comparison suggests that preschool males and females' sensory perception may be different, and that socialization and or maturation continues to have differential effects on the sexes into adulthood. 
A STUDY OF AGE AND SEX-RELATED DIFFERENCES IN THE PERCEPTION OF EMOTIONAL STIMULI

by

NANCY MELLOR CANIZIO

A thesis submitted in partial fulfillment of the requirements for the degree of

\author{
MASTER OF SCIENCE \\ in \\ PSYCHOLOGY
}

Portland State University

1982 
TO THE OFFICE OF GRADUATE STUDIES AND RESEARCH:

The members of the Committee approve the thesis of Nancy Mellor Canizio presented August 12, 1982.
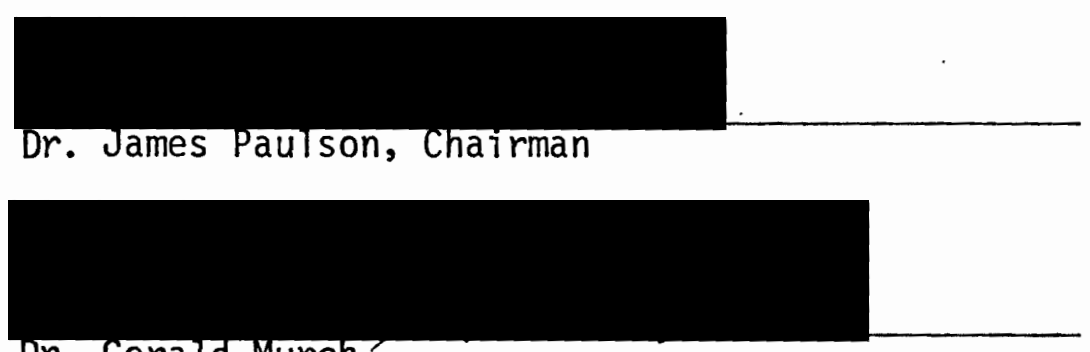

Ur. Gerald Murch

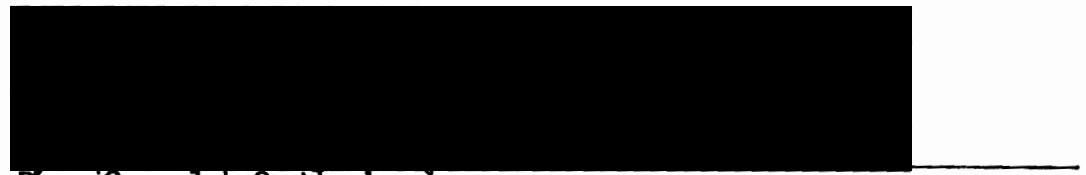

Dr. Gerald Guthrie

APPROVED:
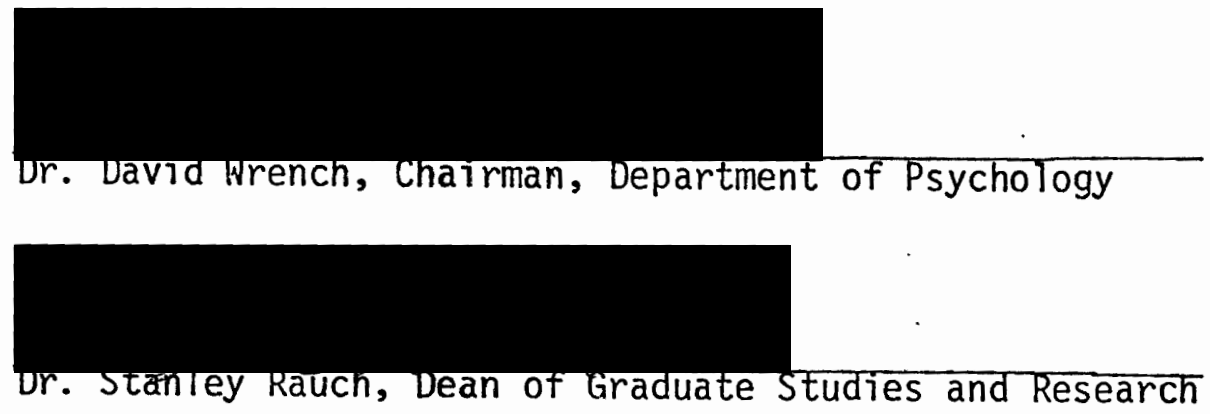


\section{ACKNOWLEDGEMENTS}

I attribute the reality of a finished product to committee chairman, Dr. James Paulson. He made statistical analysis exciting rather than painful. However, most important to me, his expressed excitement with the project made his insistence on quality less a hurdle than a goal. He handled morale and technical expertise with equal facility. Being deficient in both at times, I exploited his strength.

I wish to express appreciation to committee member Dr. Gerald Murch, who continued in that function even after his departure from Portland State to the private sector, and to committee member $\mathrm{Dr}$. Gerald Guthrie, whose child psychology course inspired the developmental component of my study. Both Drs. Murch and Guthrie generated initial design suggestions and safeguards which aided in producing interpretable results. Dr. Barry Anderson provided excellent consultation in the interpretation phase of the study.

My husband Charles Canizio and sons Casey and Jesse deserve much gratitude for standing by me during the course of this study in spite of my periodic lapses as a wife and mother. 
TABLE OF CONTENTS

PAGE

ACKNOWLEDGEMENTS . . . . . . . . . . . . . . . . $i_{i}$. .

LIST OF FIGURES

LIST OF TABLES vï

CHAPTER

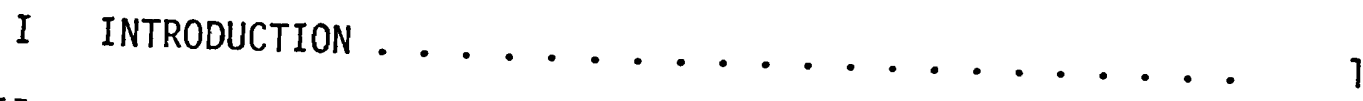

II METHOD ........................ 9

Subjects ................. 9

College

Ninth Grade

Third Grade

Preschool

Procedure Summary :............ 10

Apparatus ..................... 11

Photographs for Threshold Level

Photographs for Sensory Memory Task

Photographs for Recognition Memory Task

Validation of Stimuli

Procedure

Establishing Threshold

Sensory Memory Task

Recognition Memory Task

III RESULTS

IV DISCUSSION

Sensory Memory Task 
CHAPTER

PAGE

Recognition Memory Task.......... 46 $\checkmark$ SUMMARY ............................... 51

REFERENCES ........................ 52

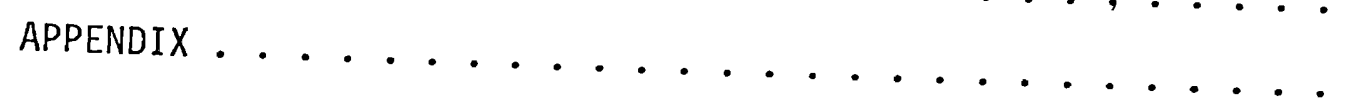




\section{LIST OF FIGURES}

FIGURE

PAGE

1. Procedure Overview for Each Subject . . . . . . . . 12

2. Typical Display of Photographs on Sensory

Memory Task ................. 14

3. The Emotional/Benign Comparișon on the Sensory

Memory Task ................ 2 28

4. The Dependent/Aggressive Comparison on the

Sensory Memory Task . . . . . . . . . . 30

5. The Dependent/Aggressive Comparison for Correct

Choices on the Recognition Memory Task . . . . . . 32 


\section{LIST OF TABLES}

TABLE

PAGE

I Description and Use of Stimuli in Dependent, Aggressive and Neutral Categories . . . . . . . . . . 15

II College Students' Validation of Stimulus Categories;

Tabulation of Responses to Questionnaire . . . . . .

III Ninth Graders' Validation of Stimulus Categories;

Tabulation of Responses to Questionnaire . . . . . . 19

IV Low, High and Average Range of Exposure Times (in Msec)

for First Identification and Threshold Level . . . . . 27

$\checkmark$ Overal1 Comparison of Correct Responses on Sensory

Memory Task ................... 25

VI Dependent/Aggressive Comparison of Correct Responses

on Sensory Memory Task . . . . . . . . . . . 26

VII Emotional/Benign Comparison of Correct Responses

on Sensory Memory Task . . . . . . . . . . . . . 27

VII Dependent/Aggressive Comparison of Errors on

Recognition Memory Task ........... 31

IX Analysis of Variance for Overall Comparison of Errors

on Recognition Memory Task . . . . . . . . . . . 34

$X$ Analysis of Variance for Emotional/Benign Comparison

of Errors on Recognition Memory Task : . . . . . . 35 
TABLE

I Dependent/Aggressive Comparison of Incorrect Choices on Sensory Memory Task . . . . . . . . . . 36

XII Emotional/Benign Comparison of Incorrect Choices on

Sensory Memory Task .............. . 37 


\section{A STUDY OF AGE AND SEX-RELATED DIFFERENCES IN}

THE PERCEPTION OF EMOTIONAL STIMULI

Developmental psychology is oriented toward resolving the mysteries of how an infant becomes an adult. Matthew Speier (1976) has labeled this orientation "the adult ideological viewpoint in studies of childhood," emphasizing the unique nature of this perspective. He suggests that research shouid focus on children as interactants with each other and with adults----adults who view them as what they should become, rather than what they are. Speier contends that these very units of children's behavior, often viewed as insignificant because of their short-term nature, might well be the most germane to a view of childhood as children see it. In like manner, Skolnick (1976) cautions against the "governing presuppositions" that guide our study of child development and socialization toward some notion of aduit performance.

To extricate the aduit-centered notion of a child's viewpoint from the child's view of reality, the area of visual perception is a logical beginning because of its importance in concept formation. Much developmental research has been focused on comparing hypothesized differences in information processing between young children and adults. An integral question for this research is whether any such differences lie in perceptual ability (organismic structure), or whether the experimental stimuli is processed differentialty (cognitive experience). This presents the age-old nature/nurture dilemma. 
Research will be reviewed suggesting organismic differences in the way children and adults handle sensory input. The nurture factor is the possible difference in meaning that identical stimuli might hold for individuals at various age levels. If age-dependent differences are found, they might thus represent organismic, cognitive or measurement variations. It is likely an interaction of all these factors exists in many developmental studies.

On the side of organic developmental difference, Rohwer (1970) made the substantial claim that "the ability to use a linguistic or verbal means for storing and preserving information emerges earlier developmentally than the ability to use visual or imagery processes for accomplishing the same ends." Furthermore, Conrad (1972) contends that preschoolers are unable to utilize a naming or labeling process to facilitate learning whether they vocalize or not. He conducted an STM experiment with subjects who were sometimes instructed to vocalize and sometimes not in the identification of familiar objects. From his results, he theorized that in children under four years, naming or verbal mediation does not occur. He also suggested that vocalizing interferes with an unstable naming development in five and six year olds impairing recall.

Neither position has withstood more carefully controlled experimentation. Jones' (1973) study of three-year-0ld children produced results showing superior performance on visual materials as compared with verbal. Visual stimuli included colored photographs rather than the line drawings of some preceding studies, the verbal and non-verbal presentation modes were clearly delineated, and pre-training was done 
to insure an understanding of the task. In the paired associate task (even when the original stimuli were presented verbally), recall was superior when probed visually. This emphasizes the preschoolers' use of imagery.

Brown (1977) attempted to replicate Conrad's study using letters instead of pictures to bias the short-term memory task toward verbal coding, and he found a phonetic effect in preschoolers evidenced by a decreased performance in coding items of high phonetic similarity even when the stimuli were presented visually. Brown emphasized the fact that previous studies have underestimated the coding flexibitity of preschoolers. These studies suggest that similar perceptual processes are functional in preschoolers as compared with older children and adults, and previous differential outcomes in recall tasks may indicate preschoolers' differing use of these resources.

Prior to the process of retrieval is the initial storing of information through some sort of coding or mnemonic process. Certainly at the visual level, and probably the other sensory levels as well, familiarity of stimuli has a significant effect on the earliest stages of visual processing (Solomon and Howes, 1951). A related factor of similar importance is the perceptual salience of stimuli. Odom and Lemond (1975) through a salience assessment procedure on four dimensions (form, color, number and position) dispute previous findings that older subjects are better able than younger subjects to attend to relevant and to ignore irrelevant information. Hagen and Hale (1973) proposed from an incidental-learning paradigm study that with increasing age, subjects have more cognitive control in selecting goal- 
relevant information and ignoring incidental information. It seems from Odom and Lemonds' study that salience affects the ability to store and recall both relevant and incidental information, and that Hagan and Hales' results might have been produced by ignoring the difference in relative perceptual salience between the two groups. Adults might have had more experience with all the stimuli and therefore were not distracted by the salience of the irrelevant stimuli as were perhaps the younger subjects who had less overall familiarity with the stimuli and a decreased chance of perceiving uniform salience. When this factor is controlled, Odom and Lemonds' study shows that both intentional and incidental recall is facilitated by a high level of assessed salience for adults as well as younger subjects.

Salience and familiarity of stimuli played a major role in Toch and Schulte's (1961) binocular rivalry experiment with police administration students. A series of violent and non-violent pairs of pictures were presented in a stereoscope, and advanced police students as well as two groups of controls were asked to identify the picture they saw. The number of violent percepts was significantly greater for advanced police administration students than for first-year poli-ce students or psychology students (the two control groups did not differ significantly from each other). The training or experience of the advanced students rather than personality variables seemed to be responsible for the significant difference because it was assumed that personality characteristics would be similar for first-year police students and the advanced group----sensitivity to violent percepts was environmentally developed rather than an inherent individual character- 
istic of men attracted to police administration study. Toch and Schulte discussed the possibility of police training removing the inhibition to perceive anti-social situations as well as the theory of an increased readiness to perceive violence. The design of the study did not permit distinguishing between these two explanations.

Wicklegren (1979) lends support to the idea of perceptual set in his discussion of a chunking process which is the hypothetical development of new nodes which are activated by a group of learned associations. He points out that expectations may influence perception by activating these nodes either at the semantic memory level through partial activation (priming) or through the feedback process to the sensory periphery. Thus in visual perception, Wicklegren suggests that roughly four nodes or ideas can be accessed at one time, but there seems to be a stratified system where one node activates another within its constituency. He cites the example of faster perception of a target letter that occurs in a word as opposed to a non-word.

Effects of expectation and/or inhibition seemed to be operative in Kagan and Moss's (1960) study conducted with adult subjects from the Fels Research Institute longitudinal population. In a tachistoscopic perception task, they found males to have a higher recognition. threshold (measured by exposure time necessary to correctly identify stimuli) than females for pictures depicting dependency. They found the converse to be true for recognition thresholds of the aggressive pictures. The inference could be made that stimuli depicting dependency is stressfur to adult males and stimuli depicting aggression is stressful to adult females, or that aggression is more salient and 
familiar to females.

Jenkins (1957) has reviewed the often contradictory literature which has sought to deal with the relationship between affective processes and perception. Bruner and Goodman (1947) offer a working definition of these affective processes by categorizing them as "behavioral" determinants or "those active adaptive functions of the organism which lead to the governance and control of all higher-level functions." In this category would fall value, need and motivation factors which Jenkins discusses as differentially affecting perception. The second major category of perceptual determinants Bruner and Goodman term "autochthonous," the "characteristic electrochemical properties of sensory end organs and nervous tissue."

The present study will compare the effect of stimuli of differing emotional content (aggressive, dependent and neutral) on the perception and recognition processes of four age groups: preschool, third grade, ninth grade, and college students. It is suggested that varying the emotional content of colored photographs will produce age and sexrelated differences in both a perception and recognition task, but that these differences will be due to "behavioral" determinants rather than age-related neural differences. The exception to this would be in size of short-term memory working space which should increase with age and produce quantitatively. greater recognition with older subjects.

Cantor (1976) has shown that the salient needs of subjects significantly affect their categorization of the interactions of individuals. In turn, Klein, Schlesinger and Meister (1951) have pointed out that values seem to affect perception most when the task is 
difficult or ambiguous. The design of this study with almost subthreshold exposure of very similar photographs thus favors value-laden perception. However, predicting the values of the groups by age and sex and the direction perceptual differences will take is most difficult because the interaction of several factors must be considered: What are the different overt vs. covert values assigned the qualities of aggression and dependency? Is there a difference in the felt or expressed concern regarding these qualities? Whether valued positively or negatively, does a "current concern" ( $K$ Iinger, 1975) with aggressive or dependent relationships determine the facility of perception? Across the considerations of value, need and concern, does intensity increase the difficulty of categorizing and associating images as Horowitz (1970) suggests?

In an attempt to integrate the various factors believed to affect perception, it is predicted that:

1. Subjects of both sexes at the preschool level will correctly identify and recognize proportionately more aggressive stimuli than dependency stimuli. It is hypothesized that there will be a salience factor involved because dominance, associated with aggression, is highty valued from the seemingly powerless position subjects at that age occupy.

2. The males of the three oldest groups witl identify significantiy more aggressive pictures than females of those groups. This is also based on a theorized value. Sex-role stereotyping suggests that males should be strong while females should be protected and taken care of. 
3. The females of the three oldest groups will identify more dependency photographs. This might be produced by both an inhibition to perceive aggressive situations as well as greater willingness to identify with dependency issues. It is not felt this difference will be in effect in the preschoor group because dependency is perhaps valued by both sexes at that age and therefore should be identified proportionately more than the neutrai stimuli.

4. There will be an age-related difference in the correlations between the perceptual task and the recognition task with the younger subjects having a positive correlation, and the older subjects of both sexes recognizing more of the emotional stimuli than the neutral only on the perceptual task.

All the predictions are based on cognition differences rather than differences in sensory equipment between the subject groups. 
METHOD

Subjects

Subjects were obtained through the educational and child care agencies of Astoria, Oregon, a town of approximately 10,000 located on the northwestern coast. A total of 72 individuals were tested on a sensory memory task, and 63 of those individuals were given a recognition memory task approximately 48 hours later.

College Age Group. Eight male and nine female subjects were obtained from psychology classes at Clatsop Community College. The ages ranged from 17 to 48 with a mean of 24.75 years. On the recognition memory task, one female was unavailable for testing. The researcher requested volunteers directly from the classroom.

Ninth Grade Group. Eight males and nine females were tested on the sensory memory task. Two females were unavailable for testing on the recognition memory task. Subjects' ages ranged from 14 to 15 years. They were obtained through a required freshman class at Astoria High School. Letters were sent home with students requesting parental permission to participate in the study. Students' and parents' questions about the study were answered in general terms by the class instructor and dean of students.

Third Grade Group. Ten male and ten female subjects participated in the sensory memory and recognition memory task. The ages ranged from 8 to 9 years. Subjects were obtained from the Astor and Gray 
Public Elementary Schools, and the Children's Center Day Care program. Preschool Group. Nine males and nine females participated in the sensory memory task, and five males and six females also participated in the second task. The ages ranged from four to five years. Subjects were obtained from the Children's Center, Josie Peper Child Care Center, and the Head Start Program by giving letters to the parents of the children requesting their permission to allow their children to participate. Five males and three females were from the Children's Center program, four males and five females were from Josie Peper, and one female was from the Head Start program.

There were nine subjects in all whose performance is not accounted for in the data. In the College group, one male subject was able to identify the pre-test pictures at the fastest exposure time so a threshold could not be obtained for him. One male and one female did not show for testing. In the Third Grade group, one female subject was dropped due to equipment problems which overexposed the test pictures. In the Preschool group, three males and two females could not complete testing because of refusal and inability to identify all the pre-test pictures.

\section{Procedure Summary}

Each subject was shown a series of ten pictures in a tachistoscope to establish an individual threshold which was defined as the exposure time necessary for the subject to correctly identify 50 percent of the stimuti. The subject's task was to match the picture shown in the tachistoscope with its copy mounted on a poster. The procedure 
used was the up-and-down method described by Dixon and Massey (1968), and will be referred to here as "establishing threshold." A more detailed explanation of the procedure is included in a separate section. Figure 1 illustrates this and the subsequent steps in the procedure. After the exposure time at threshold was established, twelve test pictures were then shown to the subject one at a time in the tachistoscope at the established exposure time, and the subject was asked to identify the pictures and an additional six never seen by the subject before. They were asked to indicate by a "yes" or "no" if they had seen the pictures before. The tachistoscope was not used in this procedure, which will be referred to as the "recognition memory task."

\section{Apparatus}

A two-field mirror tachistoscope (Gerbrands, Model T-2B-1) with one channel lighted was used. Brightness was equated at $15 \mathrm{ML}$, and the target subtended a visual angle of $24.29^{\circ}$ by $25.14^{\circ}$. The image was projected on the retina with a vertical angle of $24.29^{\circ}$ and a horizontal angle of $25.14^{\circ}$. A polaroid camera with flash attachment was used to take the test photographs. An easel with the tray $71.4 \mathrm{~cm}$ from the ground was used for mounting the posters. Seating height of the subject and table height for placement of the tachistoscope varied considerably, but the subjects were always situated so their eyes fit directly into the mask of the tachistoscope, thus controlling distance from the target. Testing environment varied from school to school, but was always conducted in a private room in the institution the subject attended when the sensory memory task was given. The recognition 


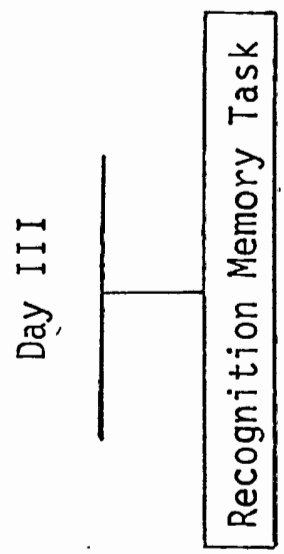

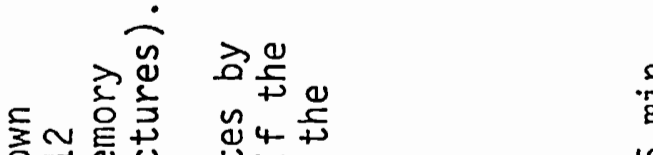

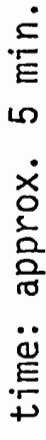

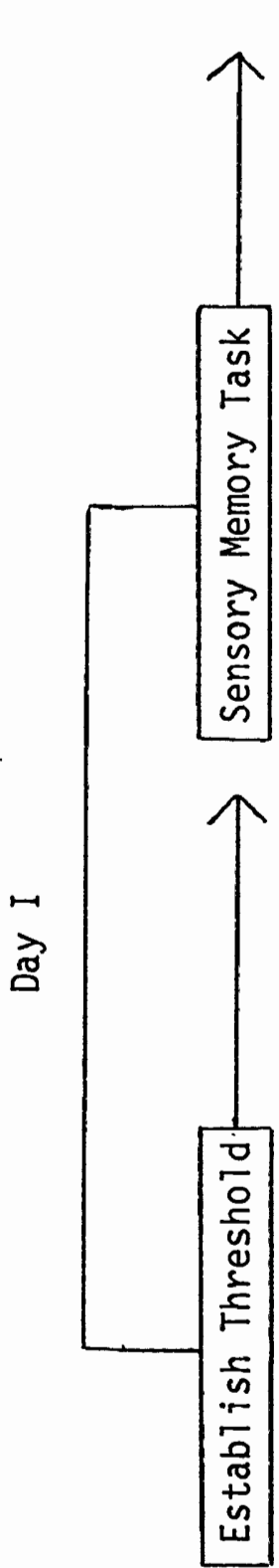

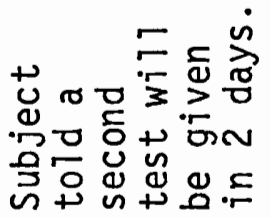

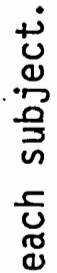

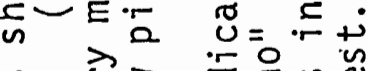

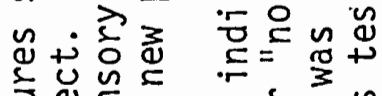

$\zeta \& 气=s^{3}$

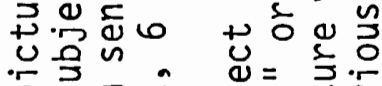

ล

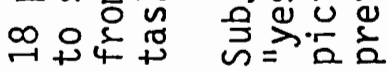

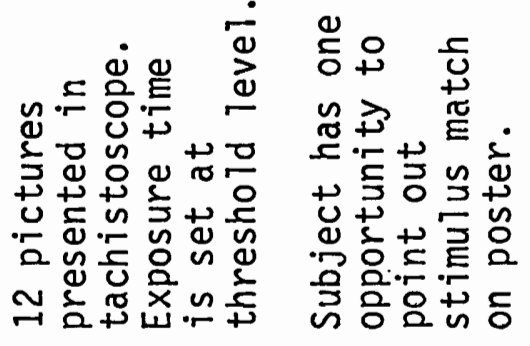

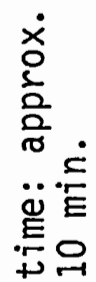

ธิ㇒

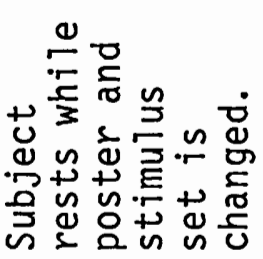

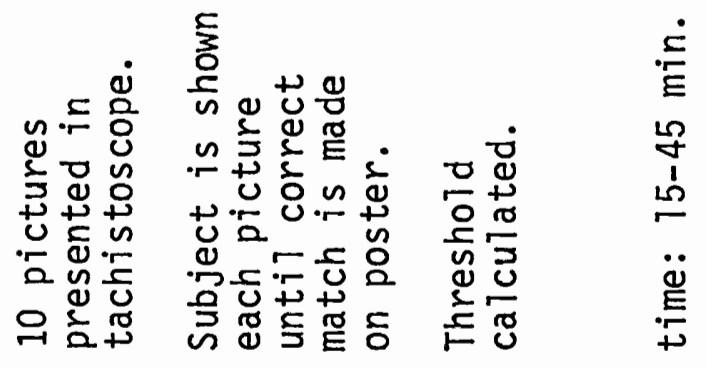


memory task was conducted in less structured settings, including a subject's home in one instance and workplace in two instances, as well as the institutions.

Photographs For Establishing Threshold. Twelve $8.8 \mathrm{~cm} \times 8.5 \mathrm{~cm}$ photographs were used in the threshold procedure. They were candid shots of children against varying backgrounds taken in color. The pictures were mounted on white poster paper measuring $70.8 \mathrm{~cm} \times 50 \mathrm{~cm}$ in clear picture-mounting tabs. The photographs were $8.5 \mathrm{~cm}$ from the top of the poster, $9.7 \mathrm{~cm}$ from the bottom, $10.5 \mathrm{~cm}$ from the left side and $8.5 \mathrm{~cm}$ from the right side. There was $5.5 \mathrm{~cm}$ between the columns, and $5 \mathrm{~cm}$ between the rows. Each column had three photographs, and each row had four. Duplicate copies of 10 of the photographs were mounted on white index cards $15.2 \mathrm{~cm} \times 10.1 \mathrm{~cm}$ for placement in the tachistoscope.

Photographs For Sensory Memory Task. Sixteen Kodacolor copies of polaroid prints were mounted on white poster paper of the same dimensions of the previous section. The photographs were $8.8 \mathrm{~cm} \times 8.5 \mathrm{~cm}$. A scaled-down copy of the poster layout is shown in Figure 2. Photograph position was randomized: Duplicates of 12 of the photographs on the poster were mounted on the $15.2 \mathrm{~cm} \times 10.1 \mathrm{~cm}$ white index cards for presentation in the tachistoscope. The subject matter of these 12 photographs included two dependent, two aggressive and two neutral poses for each sex. More detailed description of each photograph is provided in Table I. The major dependent variables were based on the identification of these 12 photographs.

Photographs For Recognition Memory Task. The original polaroid 


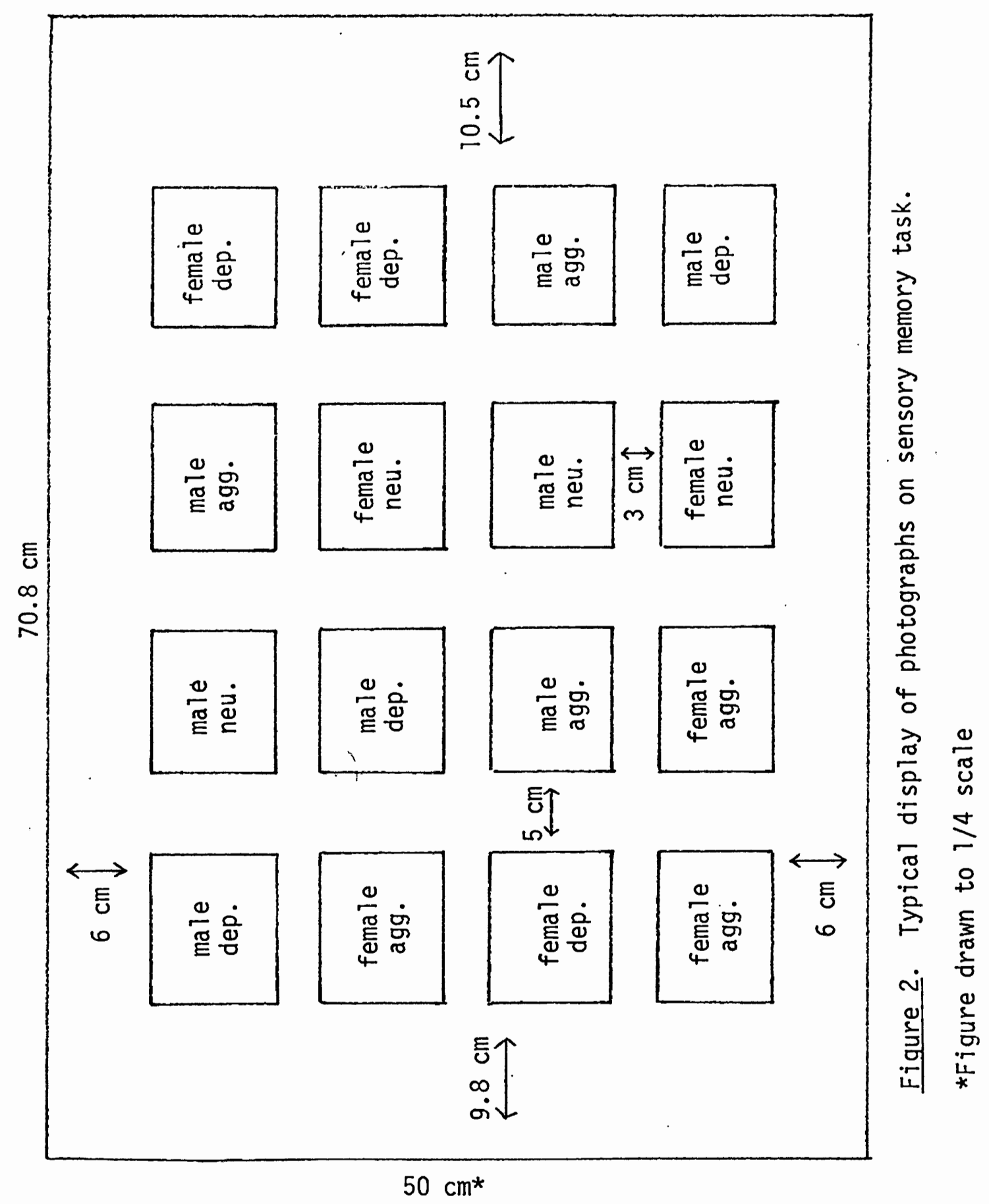




\section{TABLE I}

DESCRIPTION AND USE OF STIMULI IN DEPENDENT, AGGRESSIVE AND NEUTRAL CATEGORIES

\section{Dependent}

\# Persons

1. 2 males

2. 2 males

3. 2 females

4. 2 females

5. 2 males

6. 2 females

7. 2 males

8. 2 females

\section{Activity}

hugging, both standing

hugging, one on knees

hugging, one on knees

hugging, both standing

hugging, both standing

one holding other up

one holding other up

hugging, both standing

Aggressive

9. 2 males

10. 2 males

11. 2 females

12. 2 females

13. 2 males

14. 2 females

15. 2 males

16. 2 females pointing gun

with knife

with knife

with gun

with gun

with gun

with knife

with knife

Use

Sensory Memory (in tachistoscope \& on poster), Recognition Memory

Same as above

Same as above

Same as above

Sensory Memory (poster only)

Sensory Memory (poster only)

Recognition Memory

Recognition Memory

Sensory Memory (in tachistoscope \& on poster), Recognition Memory

Same as above

Same as above

Same as above

Sensory Memory (poster only)

Sensory Memory (poster on $7 y$ )

Recognition Memory

Recognition Memory

\section{Neutral}

17. 2 males shaking hands

18. 2 males

19. 2 females

20. 2 females

21. 2 males

22. 2 females with can of pop

looking at ring with coffee cups

with ashtray

with candle
Sensory Memory (in tachistoscope \& on poster), Recognition Memory

Same as above

Same as above

Same as above

Recognition Memory

Recognition Memory 
prints of the 12 pictures used in the sensory memory task in the tachistoscope were used. They were $8.9 \mathrm{~cm} \times 10.7 \mathrm{~cm}$. Six additional polaroid prints of the same dimensions were added. Specific content information is included in Table I.

Validation of Stimuli. The dependent, aggressive and neutral. classification of the pictures was validated in a procedure using 20 students ( 13 female and 7 male) from a college class. They were shown each picture in an overhead projector and given a choice of three responses to check (see appendix, exhibit $A$ ) as well as noting if the figures in the photograph appeared to be both male, both female, or one male and one female. Results are shown in Table II. The responses in the "other" category were interpreted by the researcher as to whether or not they fell in the appropriate category. An "other" category was not provided on the form used for the college students, but they were instructed to write comments if their perceptions didn't fit in the three categories listed, and they availed themselves of this. In three cases (photographs numbered 14, 16 and 22) the validation was poor and new stimuli were prepared. There was also poor validation of stimulus number 7, but this was not reproduced due to oversight. It was not used in the sensory memory task.

The 22 resulting stimuli were presented to a ninth grade class of nine males and ten females by passing them around the room because of the previous poor visibility in the projector. An "other category was included on the response form (see appendix, exhibit B) which had only been offered verbally to the College group. Again, the written comments in this category were interpreted by the researcher as to whether or 


\section{TABLE II}

VALIDATION OF STIMULUS; TABULATION

OF RESPONSES TO

QUESTIONNAIRE.

College Students ( 13 females and 7 males) a

Nominally Dependent Photographs

Stimulus

$\#$

Category Checked

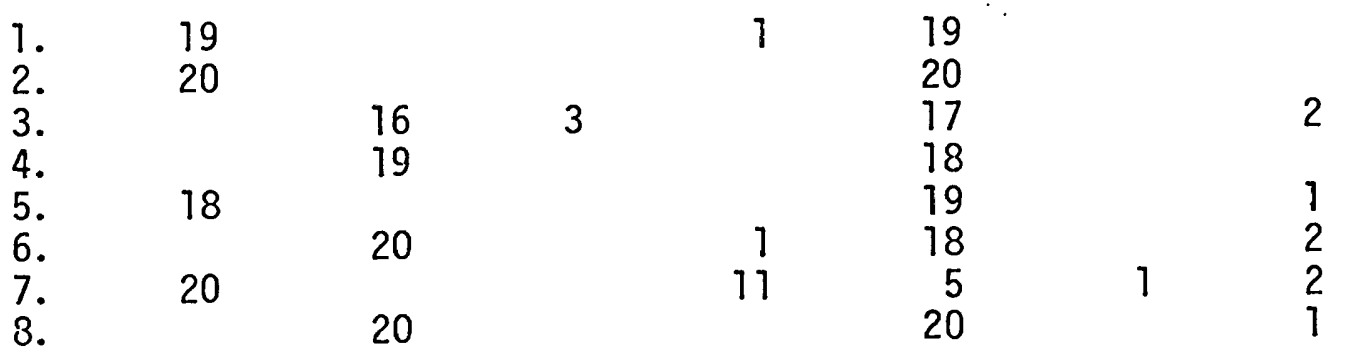

Nominally Aggressive Photographs

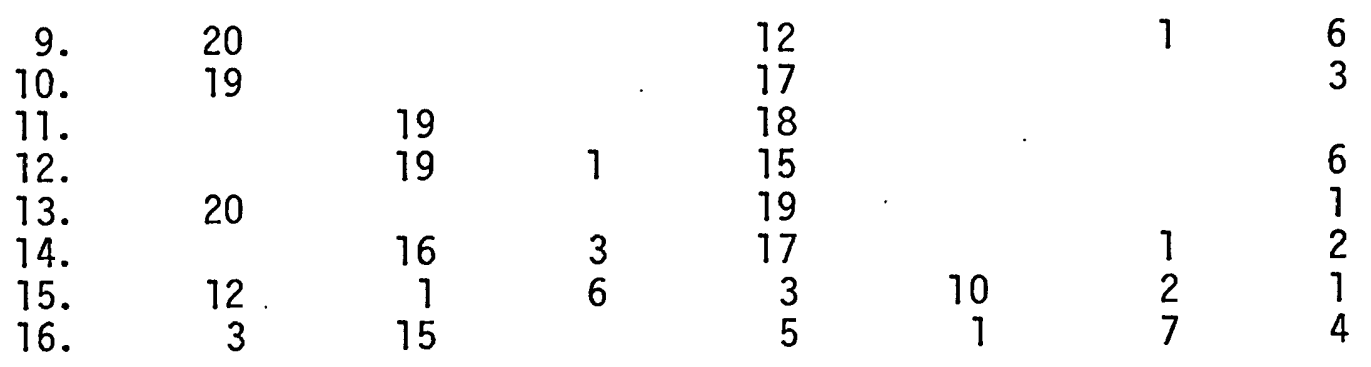

Nominally Neutral Photographs

$\begin{array}{rrrrrrr}17 . & 18 & & & 2 & 12 & 7 \\ 18 . & 20 & & 2 & 1 & 15 & 3 \\ 19 . & 1 & 18 & 3 & 8 & 4 \\ 20 . & & 19 & 1 & 2 & 14 & 2 \\ 21 . & 20 & & 2 & 8 & 16 & 3 \\ 22 . & & 18 & & 5 & 3\end{array}$

aSome students checked more than one descriptive category and some left items blank. 
not they fell in the appropriate category of the stimulus. Validation results for the Ninth grade qroup are shown on Table III.

\section{Procedure}

Establishing Threshold. Prior to the testing from which the dependent variables were gathered, a pre-test was given each subject to establish their individual threshold level. The group of 10 colored pictures of children against various backgrounds was used for this purpose. The pictures were shuffled for randomization and the first picture was presented at an exposure time in the tachistoscope which was believed to be below the subject's threshold. The initial exposure time varied according to the subjects' ages as there was found to be wide variability in threshold level, with the preschoolers' threshold being comparatively high.

The College group was the first population tested, and when attempting to establish threshold for the first subject, he was able to identify the pre-test pictures at the fastest exposure time setting on tachistoscope. Because of this, four sheets of blue plastic filters were placed in the eye opening to reduce visibility. When the Preschool group was tested, subjects began tiring on the pre-test because visibility was so difficult for them with the filters. They began to ask to leave the experiment prior to finishing the test. Thus, approximately halfway through the preschool population, the filters were removed and the remainder of the preschool group was tested without filters. This served to increase the number of correct identifications for subjects without filters, but because the fundamental dependent 
TABLE III

VALIDATION OF STIMULUS CATEGORIES;

TABULATION OF RESPONSES

TO QUESTIONNAIRE

Ninth Grade Students ( 9 males, 10 females) ${ }^{a}$

Nominally Dependent Photographs

Stimułus

\#

Male Female

\begin{tabular}{cr}
\hline Both & Anger \\
1 & 1 \\
& 1
\end{tabular}

Category Checked

$1 . \quad 18$

2. 18

3.

4.

19

5.

6.

7.

18

8.

19

18

18

18

Nominally Aggressive Photographs

$\begin{array}{rr}9 . & 19 \\ 10 . & 18 \\ 11 . & \\ 12 . & \\ 13 . & 19 \\ 14 . & 1 \\ 15 . & 18\end{array}$

16.

$17 . \quad 19$

$18 . \quad 17$

19.

20.

21.

22.
13

19

16

18

15

17

17

19

16

$\begin{array}{rr}1 & 13 \\ 1 & 11 \\ & 15 \\ 1 & 13 \\ & 12 \\ & 17 \\ 3 & 7 \\ & 13\end{array}$

$\begin{array}{ll} & 4 \\ 3 & 4 \\ & 3 \\ & 5 \\ 1 & 6 \\ 1 & 1 \\ 2 & 7 \\ 1 & 4\end{array}$

Need Nothing other

15

12

17

7
23

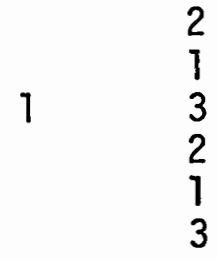

Nominally Neutral Photographs

asome students checked more than one descriptive category and some left items blank. 
variables in the study involve within-subject contrasts of response to aggressive, dependent, and neutral stimuli, a between-subjects difference should not invalidate the preschool data.

The initial pre-test picture was presented at the anticipated threshold level of the subject, and exposure time was increased by two milliseconds until a correct identification was made. The second pretest picture was presented at two milliseconds less exposure time than the time of the previous correct identification. Either the time was recorded if a correct identification was made or the exposure time was increased by two milliseconds until this occurred. Each correct identification meant placement of the next pre-test picture in the tachistoscope and presentation at two milliseconds less exposure time than the previous correct identification. Threshold was computed on the basis of nine pre-test pictures, throwing out the first one and using the formula $x=y \pm 1 / 2 d$, where $x$ is the mean of the exposure times for successful identification of stimuli or incorrect identification of stimuli, whichever is less, and $1 / 2 d=1$ since there is a two millisecond increment. One is added if the formula is based on failures and subtracted if based on successes (Dixon and Massey, 1968). The range of exposure times and threshold levels are shown in Table IV.

Prior to beginning this task, the subject was seated in front of the tachistoscope with an easel supporting a poster with 12 colored photographs of children positioned to the left of the tachistoscope. The subject's name, age and vision information was recorded. The latter included whether or not the subject used corrective lenses and if there was any indication of color blindness. Instructions were given that a 
TABLE IV

LOW; HIGH AND AVERAGE RANGE OF

EXPOSURE TIMES (IN MSEC)

FOR FIRST IDENTIFICATION

AND THRESHOLD LEVEL

College Group

Males

Fema Tes

First
Identification Threshold

Low

14

49

14

66

High

800

849

278

296

Average

150

228.4

95.8

134.8

Ninth Grade Group

Low

16

57
150
106.9

32

50

High

132

60.6

138

210

Average

106.9

68.4

122.7

Third Grade Group

Low

32

High

370

109

74

109

Average

167.8

905

296

420

153.8

220.5

Preschool Group

Low

12

14

22

41

High

910

929

844

868

Average

(Total)

407.1

419.2

368.2

444.4

Average

(Without

Filters)

43.6

54.6

91

205.5

Average

(With

Filters)

861.5

875

590

635.6 
series of pictures would be shown one at a time in the machine so that they could barely be seen, but as soon as the subject thought they knew which picture was being shown, they were to point it out on the poster. Guessing, even if the subject wasn't entirely sure was encouraged and was not penalized. The order of presentation as well as position on the poster was randomized by shuffling the stimuli before each subject was tested. The pre-test was then conducted in the manner described. The subject was told he could rest while the researcher calculated threshold level.

Sensory Memory Task. A second poster was then placed on the easel containing the 16 colored photographs made up of three "dependent" male interactions, three "dependent" female interactions, three "aggressive" male interactions, three "aggressive" female interactions, two "neutral" female interactions and two "neutral" male interactions. To reduce the possibility of identification by elimination, one dependent female and dependent male interaction as well as one aggressive male and one aggressive female picture on the poster was not presented in the tachistoscope.

Duplicates of the 12 pictures on the poster were each presented once in the tachistoscope at the exposure time determined in the pretest situation to be threshold leve1. Directions given to each subject were that each picture would be presented once and they were to try to match the one in the tachistoscope by pointing to its duplicate on the poster. They were urged to guess if they were unsure. Stimuli were numbered on the back and the number. of the stimulus they guessed each time was recorded. The number of correct identifications in each 
category - dependent, aggressive and neutral - were tabulated and used in the analysis of the results. The number of incorrect identifications in each stimulus category was also tabulated and used in an analysis. Recognition Memory Test. An arrangement was made to set up a second testing time with each subject. Approximately two days later, with some exceptions, they were shown 18 pictures including the 12 shown in the tachistoscope. Instructions were given that some of the pictures had been shown to them in the previous test and some were photographs they had never seen. They were asked to say "yes" if they had seen the picture presented and "no" if they had not. The pictures were the original polaroid prints from which the copies used in the previous task had been made. The six new pictures included two in the "dependent," two in the "aggressive" and two in the "neutral" category, one each with females and one each with males. Each picture was handed to them and they were asked to place it face down when they were finished responding. Order of presentation was randomized by shuffling the pictures. Response was recorded with the number of each stimulus presented. 


\section{RESULTS}

Age bySex analyses of variance were calculated on three dependent variables abstracted from the correct responses of the subjects to the three different categories of stimuli. This resulted in six ANOVA's: three for the sensory memory task and three for the recognition memory task. The dependent variables were a) the total number of correct identifications for each subject, which will be referred to as the overall comparison; b) the number of correct identifications of dependent stimuli minus the number of correct identifications of aggressive stimuli - the dependent/aggressive comparison; and c) the mean of the number of correct identifications for dependency and aggressive stimuli minus the number of correct neutral identifications - the emotional/ benign comparison. Tables V, VI and VII show the means and standard deviations and the results of the analyses of variance for the respective dependent variables.

A significant sex-by-age interaction effect occurred in the emotional/benign comparison on the sensory memory task. Figure 3 illustrates this interaction. Females in preschool correctly identify less of the emotional stimuli (aggressive and dependent) than neutral. By third grade this is reversed and continues with increasingly greater difference favoring emotional stimuli through college age. Males in preschool correctly identify more of the emotional stimuli in comparison with neutral, but the difference declines until college age when 


\section{TABLE V}

OVERALL COMPARISON OF CORRECT RESPONSES

ON SENSORY MEMORY TASK

Mean and Standard Deviation Scores

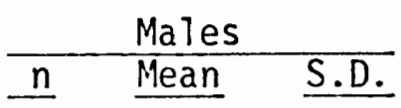

\section{College Group}

Ninth Grade Group

3rd Grade Group

Preschool Group

$\begin{array}{rrr}8 & 7.88 & 2.10 \\ 8 & 7.75 & 1.67 \\ 10 & 7.50 & 2.80 \\ 9 & 8.22 & 2.91\end{array}$

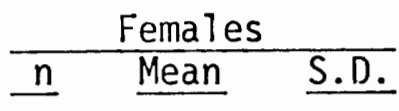

$\begin{array}{lll}9 & 9.11 & 3.14\end{array}$

$\begin{array}{lll}9 & 8.33 & 2.12\end{array}$

$\begin{array}{lll}10 & 7.30 & 3.02\end{array}$

$\begin{array}{lll}9 & 6.11 & 2.03\end{array}$

Analysis of Variance

SS $\quad \underline{\text { df }} \quad \underline{M S} \quad \underline{F} \quad \underline{P}$

Age

19.63

3

6.54

.98

Sex

.29

1

.29

.04

Age $x$ Sex

28.17

3

9.39

1.35

Within

446.99

64

6.98

Total

495.07

71 
TABLE VI

DEPENDENT/AGGRESSIVE COMPARISON OF CORRECT

RESPONSES ON SENSORY MEMORY TASK

Mean and Standard Deviation Scores,

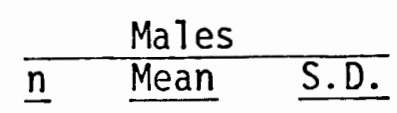

College Group

Ninth Grade Group

3rd Grade Group

Preschool Group

$8 \quad 4.88 \quad 1.13$

$8 \quad 5.25 .1 .39$

$\begin{array}{lll}1.0 & 4.00 \quad 1.05\end{array}$

$\begin{array}{lll}9 & 3.89 & 1.27\end{array}$

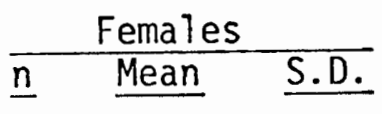

$\begin{array}{lll}9 & 4.22 & 1.39\end{array}$

$9 \quad 5.56 \quad 1.59$

$\begin{array}{lll}10 & 4.50 & 1.35\end{array}$

$\begin{array}{lll}9 & 3.89 & 1.17\end{array}$

aThese are scaled scores where $4=$ no difference, $4+=$ more dependent, 4- = more aggressive.

Analys is of Variance

Age

Sex

Age $x$ Sex

Within

Total

$\star p<.025$ $\underline{\text { SS }}$

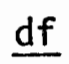

22.39

.03

3.41

108.32

134.15

64

71
MS

7.46

.03

1.14

1.69
F

4.41

.02

.69 
TABLE VII

EMOTIONAL/BENIGN COMPARISON OF CORRECT

RESPONSES ON SENSORY MEMORY TASK

Mean and Standard Deviation Scores ${ }^{a}$
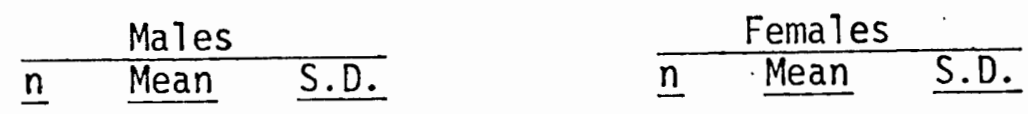

College Group

$\begin{array}{lll}8 & 3.38 & 1.51\end{array}$

$\begin{array}{lll}9 & 5.44 & 1.67\end{array}$

Ninth Grade Group

$\begin{array}{lll}8 & 4.25 & 2.55\end{array}$

$\begin{array}{lll}9 & 4.67 & .87\end{array}$

3rd Grade Group

$\begin{array}{lll}10 & 4.80 \quad 1.75\end{array}$

$\begin{array}{lll}10 & 4.30 & 1.57\end{array}$

Preschool Group

$\begin{array}{lll}9 & 5.00 \quad 1.97\end{array}$

$\begin{array}{lll}9 & 3.44 & 1.42\end{array}$

aThese are scaled scores where $4=$ no difference, $4+=$ more emotional, 4- = more benign.

Analysis of Variance

Age

Sex

Age $x$ Sex

Linear $x$

linear

Residual

Within

Total

$* p<.05$

$* * p<.01$

\section{SS}

1.04

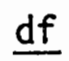

3

1

37.64

29.71

1.93

223.65

256.53

71
MS

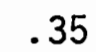

$\underline{F}$

.10

.20

.06

10.55

3.02

29.71

8.5

.97

.28

3.50

p. 


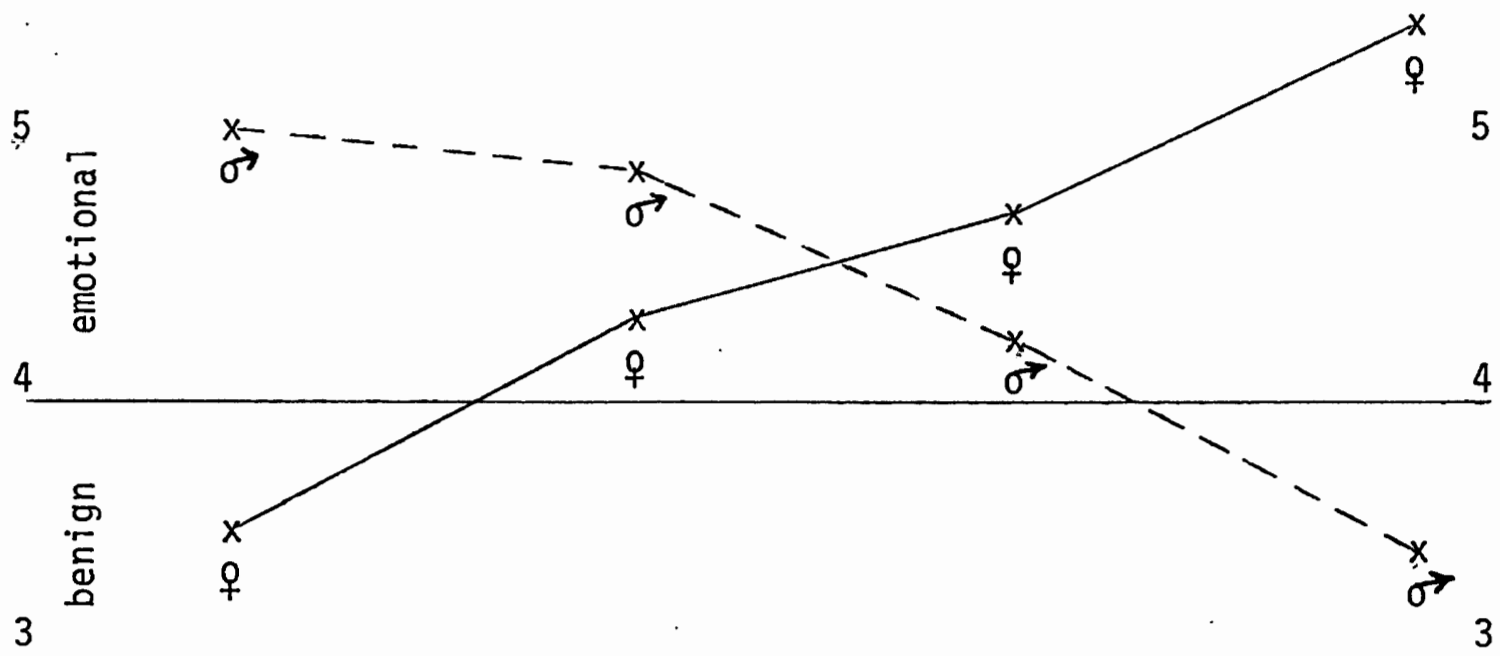

2

preschool

3rd grade

9th grade

college

Age Group

Figure 3. The emotional/benign comparison of correct choices on the sensory memory task. Mean differences shown as scaled scores, $4=$ no difference. 
males identify slightly less emotional than neutral stimuli. The analysis of variance in Table VII illustrates that the linear-by-linear component of interaction accounts for almost all of the significant variability.

A significant age effect occurred in the dependent/aggressive comparison on the sensory memory task. Ninth grade males and females correctly identified significantiy more dependency pictures than preschoolers and third graders. A t-test for differences among several means reveals that there was not a significant difference with the college age group. Figure 4 illustrates these results.

A significant age effect in the opposite direction occurred in the recognition memory task with the dependent/aggressive comparison. The means and standard deviations and results of the analyses of variance are shown in Table VIII. Figure 5 shows that in the recognition task the ninth graders identify significantly less dependency pictures on the dependent/aggressive contrast, whereas there was no significant difference for the other age groups on that comparison. A t-test for differences among several means was used to determine that the ninth graders' decreased identification of dependency pictures was significantly more marked than for the other age groups. This effect occurred from both more false recognitions and more recognition omissions of dependency pictures than for aggressive pictures in the ninth grade group. On the same dependent/aggressive contrast, male and female college students also had more false recognitions of dependency stimuli but less recognition omissions than the same "miss" type errors for aggressive stimuli. This resulted in a nonsignificant 


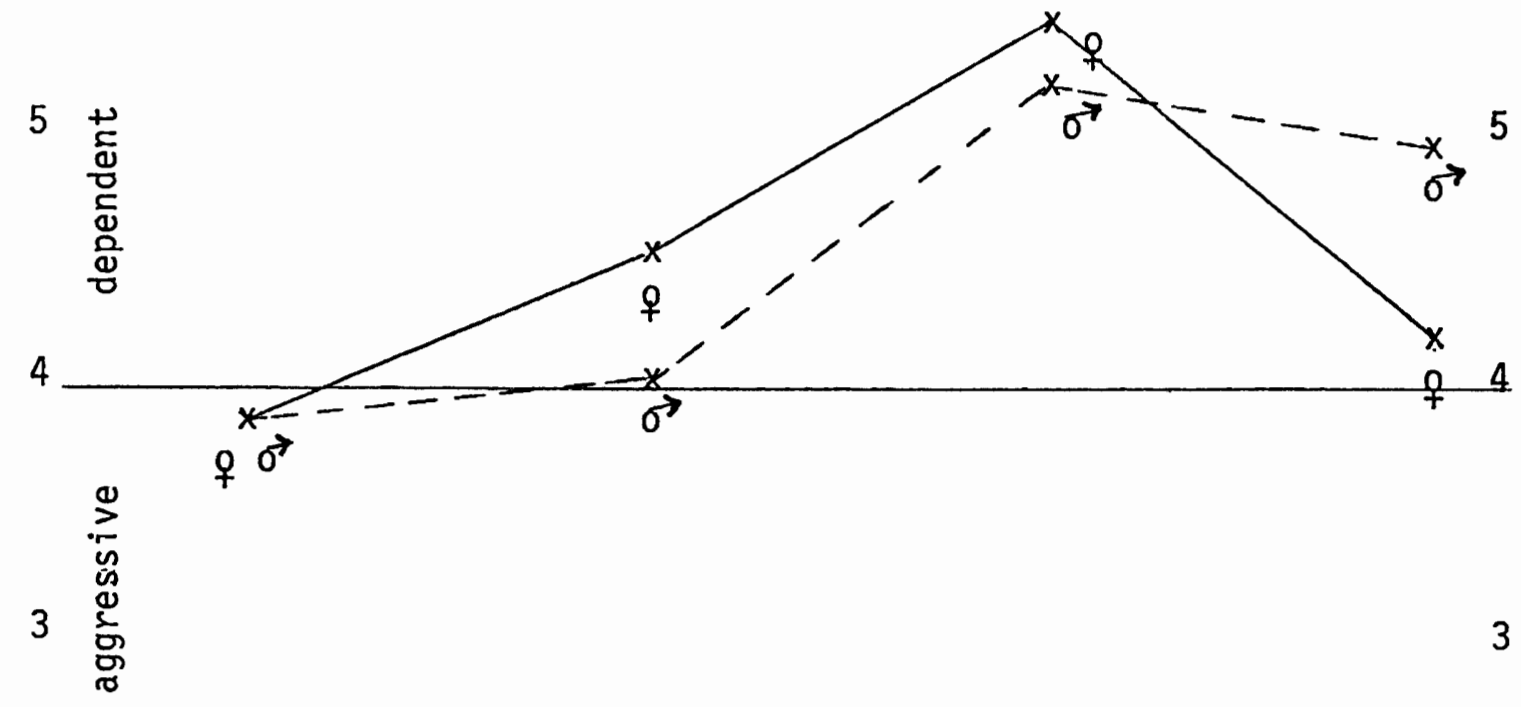

2

preschool

3rd grade

9th grade

college

Age Group

Figure 4. The dependent/aggressive comparison of correct choices on the sensory memory task. Mean differences shown as scaled scores where $4=$ no difference. 
TABLE VIII

DEPENDENT/AGGRESSIVE COMPARISON OF ERRORS

ON RECOGNITION MEMORY TASKa

Mean and Standard Deviation Scores

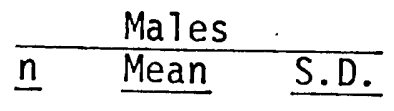

College Group

Ninth Grade Group

3rd Grade Group

Preschool

$\begin{array}{rrr}8 & 3.75 & 1.28 \\ 8 & 4.88 & .99 \\ 10 & 4.40 & .70 \\ 5 & 4.40 & .89\end{array}$

$\frac{\text { Females }}{\text { n } \quad \text { Mean } \quad \text { S.D. }}$

$\begin{array}{lll}8 & 3.63 & 1.42\end{array}$

$\begin{array}{lll}7 & 4.86 & .69\end{array}$

$\begin{array}{lll}10 & 3.60 \quad .97\end{array}$

$\begin{array}{lll}6 & 3.67 \quad .52\end{array}$

arrors were the total \# of false "yes's" and false "no's."

Analys is of Variance

$\begin{array}{lrrrrr} & \underline{\text { SS }} & \text { df } & \text { MS } & \text { F } & \text { p } \\ \text { Age } & 11.26 & 3 & 3.75 & 3.124 & \text { * } \\ \text { Sex } & 2.60 & 1 & 2.60 & 2.16 & \\ \text { Age x Sex } & 1.82 & 3 & .61 & .50 \\ \text { Within } & 64.84 & 54 & 1.20 & & \\ \text { Total } & 80.51 & 61 & & & \\ \text { * } p<.05 & & & & & \end{array}$




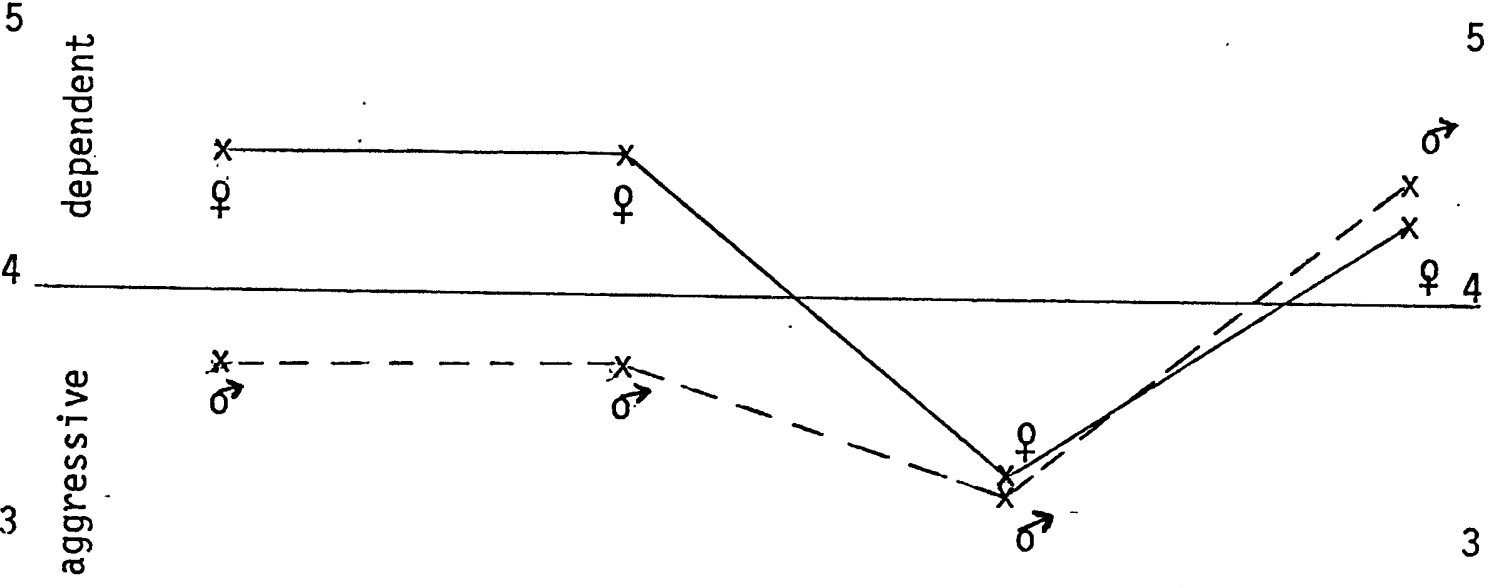

2

preschool

3rd grade

9th grade

college

Age Group

Figure 5. The dependent/aggressive comparison of correct choices on the recognition memory task. Mean differences shown as scaled scores where $4=$ no difference. 
difference on the dependent/aggressive comparison for the college group. Third graders were close on numbers of errors for all three categories and also resulted in no significant difference on the comparison. The subject loss from the preschool group (four males and three females) was high enough to make questionable the validity of their data. Also, of the five males and six females that were tested, six subjects said "yes" to all the pictures presented, and most of these subjects barely looked at the pictures before giving an answer. The results of the preschool group cannot be meaningfully interpreted on the recognition memory task for these reasons.

In the analysis of variance in the overall comparison of total number of correct identifications, there was no significant source of variation (see Table IX). This suggests that the method for estab1ishing threshold was effective in correcting for the variation of visual acuity of the four age groups. There was also no significant source of variation in the emotional/benign comparison on the recognition memory task (Table $X$ ).

A dependent/aggressive and emotional/benign comparison was abstracted from the incorrect pictures chosen on the sensory memory task and analyzed by analyses of variance. The means and standard deviations and results of the ANOVA's are shown on Tables XI and XII. There were no significant sources of variation in either ANOVA. 


\section{TABLE IX}

ANALYSIS OF VARIANCE FOR OVERALL COMPARISON

OF ERRORS ON RECOGNITION MEMORY TASK

SS $\quad$ df $\quad \underline{M S} \quad \underline{F} \quad \underline{p}$

Age

28.58

3

9.53

2.49

Sex

.47

1

.47

.12

Age $x \operatorname{Sex}$

1.34

3

.45

.12

Within

206.71

54

3.83

Total

237.10

61 
TABLE $X$

ANALYSIS OF VARIANCE FOR EMOTIONAL/BENIGN COMPARISON OF ERRORS ON RECOGNITION MEMORY TASK

SS $\quad \underline{\text { df }} \quad \underline{M S} \quad \underline{F} \quad \mathrm{p}$

Age

5.81

3

1.94

.83

Sex

5.88

1

5.88

2.51

Age $x$ Sex

4.80

2

1.60

.68

Within

126.34

54

2.34

Total

142.83

61 


\section{TABLE XI}

DEPENDENT/AGGRESSIVE COMPARISON OF INCORRECT

CHOICES ON SENSORY MEMORY TASK

Mean and Standard Deviation Scores ${ }^{a}$

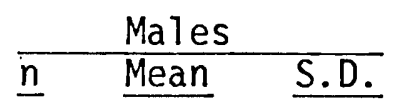

College Group

Ninth Grade Group

3rd Grade Group

Preschool Group

$8 \quad 11$

2.51

$8 \quad 8.75$

2.71

109

2.58

$\begin{array}{lll}9 & 9.56 & 1.81\end{array}$

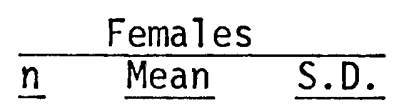

$\begin{array}{lll}9 & 10.11 & 2.47\end{array}$

$\begin{array}{lll}9 & 11.22 & 2.11\end{array}$

$\begin{array}{lll}10 & 9.40 \quad 2.46\end{array}$

$\begin{array}{lll}9 & 9.44 & 2.83\end{array}$

aThese are scaled scores where $9=$ no difference, $9+=$ more dependent, 9- = more aggressive.

Analysis of Variance

SS

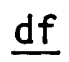

MS

$\underline{F}$

$\mathrm{p}$

Age

18.88

3

6.29

.93

Sex

3.90

1

3.90

.58

Age $x$ Sex

27.71

3

9.24

1.36

Within

433.88

64

6.78

Total

484.37

71 
TABLE XII

EMOTIONAL/BENIGN COMPARISON OF INCORRECT

CHOICES ON SENSORY MEMORY TASK

Mean and Standard Deviation Scores ${ }^{a}$

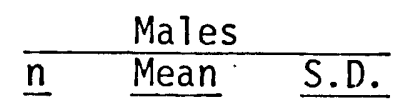

College Group

Ninth Grade Group

3rd Grade Group

Preschool Group $\begin{array}{lll}8 & 11.5 & 1.93\end{array}$

$8 \quad 12.00 \quad 5.07$

$\begin{array}{lll}10 & 13.4 \quad 2.80\end{array}$

$9 \quad 12.00 \quad 5.05$

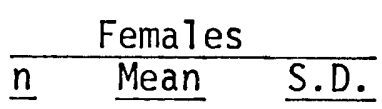

$\begin{array}{lll}9 & 10.78 & 3.53\end{array}$

$\begin{array}{lll}9 & .13 & 4.12\end{array}$

$\begin{array}{lll}10 & 12 & 2.63\end{array}$

$\begin{array}{lll}9 & 12.33 \quad 3.28\end{array}$

aThese are scaled scores where $9=$ no difference, $9+=$ more emotional, 9- = more benign.

Analysis of Variance

\begin{tabular}{lrrrrr} 
& \multicolumn{1}{c}{ SS } & df & \multicolumn{1}{c}{ MS } & \multicolumn{1}{c}{. } & p \\
Age & 45.77 & 3 & 15.26 & 1.08 & \\
Sex & .72 & 1 & .72 & .05 \\
Age x Sex & 15.36 & 3 & 5.12 & .36 \\
Within & 907.32 & 64 & 14.18 & \\
Total & 969.17 & 71 & &
\end{tabular}




\section{DISCUSSION}

\section{Sensory Memory Task}

The results of the sensory memory task support the hypothesis that varying the emotional content of visual stimuli will produce age and sex-related differences in perception as measured by number of correct identifications. Once threshold level, defined as the exposure time necessary to identify $50 \%$ of the stimuli, was equated for each subject, there was no difference in the overall number of correct identifications for each age group. There were no significant differences in the frequency of incorrect response between the different stimulus categories. Thus, the ninth graders' relatively large number of correct identifications of dependent stimuli on the dependent/ aggressive comparison, point toward a perceptual explanation of these significant results rather than an explanation in terms of response bias. For a response bias to be operative, it would seem a significant difference among incorrect choices would have resulted.

The direction of the results runs counter to the findings of Kagan and Moss (1960) that adult males have a higher recognition threshold for dependency pictures than their female peers and the latter have a higher recognition threshold for aggressive pictures than their male peers. Male college students in the present study had in fact more correct identifications of dependency stimuli on the dependent/ aggressive comparison, although it was not a significant difference. 
However, there are significant design differences between the present study and Kagan and Moss' work, and these reduce the validity of any comparisons between the two. Kagan and Moss presented only dependent and aggressive pictures (no benign category), and the longitudinal population was only tested on the tachistoscopic task as adults. The most critical design difference was the fact that Kagan and Moss presented the pictures at seven pre-established exposure times rather than individualizing threshold levels as done in the present study. Table IV shows that the average threshold level for college females (134.78) as measured by exposure time in milliseconds is lower than that for males (228.38). If this difference is significant and found to be true in Kagan and Moss' population, it could have confounded their results. If the female subjects did view the pictures in Kagan and Moss' study primarily above threshold, then their results may have been produced by a response suppression rather than by perceptual sensitivity differences between men and women. As mentioned however, there were no significant differences in the frequency of incorrect responses - between the different stimulus categories in the present study, thus not even the response preferences found in Kagan and Moss' study are evident here. It remains speculative whether this is due to a change in the population since 1960, a sampling difference, or most likely a product of the many design differences. The fact that there were no significant sex differences at any age level on the comparative number of dependent and aggressive identifications on either the sensory memory or recognition memory tasks lends weight to the idea that design differences were responsible for the contrasting results. 
The significant effect for ninth graders on the dependent/aggressive comparison where both males and females had comparatively greater accuracy in identification of dependency stimuli seems to support the findings of Toch and Schulte (1961) that training and conditioning can affect perceptual acuity. During the procedure in which ninth graders validated the stimuli (none served as subjects), there were audible comments from some students regarding the dependency scenes and their possible homosexual implications. There is ample evidence that significant hormonal changes are a part of adolescence. Brecher (1971) cites the increased testosterone levels in both males and females. There is genital development, secondary sexual maturation, and in females, the onset of menses. The remarks of the ninth graders reflecting their socialization, paired with their biological development at that age, would suggest that sexuality is a significant issue for them. (Separating maturational and conditional influences would be a significant task.) The dependency scenes were certainly interpreted sexually by some subjects, and it is to be expected on a more frequent basis than either the aggressive or benign scenes. The police academy students of Toch and Schulte's study perceived violent pictures with greater frequency than the non-violent scenes in a binocular rivalry test, suggesting that experience with a subject heightens perception of it. Adding to the validity of this explanation (emerging sexuality in adolescence and perception of dependency scenes that depict closeness and possibly sexuality) is the fact that the college group was not significantly different in their response on the dependent/aggressive comparison from the ninth grade group. Because the college females 
had almost equal perception of aggressive and dependency stimuli, that age group was not significantly different from the preschool and third grade groups, while the results of the ninth grade group were. It can be theorized that sexuality remains a more potent issue for adults than for the two youngest populations in the study, however increasing. familiarity with sexual stimuli may serve to reduce the novelty of any implied sexuality in the dependency scenes and eliminate the comparatively more accurate perception of it in the adult subject group.

Berelson and Steiner (1964) indicate that perceptual selection and organization is affected by expectations, motives and needs in play at the time. In an ambiguous field, the authors claim motivation and subjective importance of the stimulus increases an individual's perception of the relevant subject. Besides sexual connotations drawn from the dependency scenes, it seems ninth graders generated a broader range of associations to the dependency stimuli including "happy, sad, caring, loving," etc., than the college group which also validated the stimuli. Perhaps the ninth grade population which typically experiences a new school setting, increased need for independence, the separation process from family, and emerging sexuality, viewed the dependency stimuli with more associative strength. Corteen (1969) states that items with a greater response factor, i.e., chance of association, "will produce more viable dynamic traces within the general context of the item set." Supposedly, the greater the associative strength, the greater the number of pathways to recall the item.

There is also the possibility that the ninth grade subjects brought to the testing situation a set of expectations creating an 
artifactual effect that would not hold true for ninth graders generally. Initially, when receiving the letters requesting permission for their children to participate in the experiment, some parents phoned the highschool to find out if their children would be shown pornographic. pictures. (The wording of the letter requesting subjects was sub-. sequently changed from "photographic pictures of adults" - Exhibit $C$ in the addendum, to "a series of pictures" - Exhibit D in the addendum.) The Dean of Students fielded these questions, but it is expected that parents and teenagers discussed the project in more depth than the other subject groups, especially with regard to any sexual implications. To compound this pre-testing effect, many of the subjects were drawn from the same class. Although this was also true for the college group, it is likely that ninth graders are a more cohesive peer group in a one-highschool town, and would have greater opportunity to discuss the research with each other prior to becoming a subject. There is not a significant difference between the ninth grade and college age group in any event which lends plausibility to a perceptual conditioning or priming effect. With the exception of one subject, college subjects were all drawn from the same institution and primarily from the psychology classes of that institution. The validation of stimuli was conducted only at the highschool and college, and comments generated from that process in the classes could have circulated around the institutions prior to testing individual subjects.

The significant age-by-sex interaction on the sensory memory task contradicts the hypothesis that both sexes would have more accurate perception of the aggressive stimuli as compared with perception of the 
benign and dependent stimuli. Instead, the preschool male and college female populations had heightened perception of both aggressive and dependency stimuli (emotional) and comparatively less accurate perception of the benign stimuli. Jersild (1935) cites sex-related differences in the display of aggression. in the preschool environment with four-year-old males exhibiting more hitting behavior and four-year-old females doing more screaming. The dependent and some of the aggressive stimuli involve bodily contact with implied action, and this could be a salient attraction for the preschool males. Feshbach and Feshbach (1972) cite the evidence that younger nursery school children manifest more physically-aggressive responses, but with increasing age, this aggressiveness is gradually inhibited to conform with culturally acceptable expressions of behavior. They indicate physical aggression is less tolerated for girls. and verbal aggression is more evident in their behavior. The neutral pictures of this study imply a verbal transaction: two women facing each other with a coffee cup and two men facing each other with a can of soda pop. This may have been responsible for the females at the preschool level having an increased identification rate for these photographs.

Another possible differentiating feature of the stimuli is that the aggressive and dependent pictures have more variety in the posing of the individuals, whereas the benign pictures as mentioned are all with two individuals standing slightly apart looking at each other. This could have weighted the emotional pictures toward a spatial mnemonic because of more distinct visual differentiation and the benign pictures with less visual variation toward some other mnemonic. Kurdek 
and Rodgon (1975) found sex differences in perceptual and affective perspective taking tasks. Perceptual perspective taking involved replicating the position of a disk in front of the subject in the identical position it faced the experimenter. In the appropriate affective perspective task, the response of the subject pictured was congruent with the story line: happy face on boy receiving favorite ice cream cone. The inappropriate affective perspective task would picture a sad face on the boy under the same condition. Males had superior performance on perceptual and affective perspective taking while females projected their own responses more often in the inappropriate affective perspective tasks. The authors theorize that it might be indicative of males' accelerated development of mechanicalspatial skills and females' accelerated verbal skills development. The inappropriate affective perspective tasks had narrative interpretations that would result in perception of different affect than that apparent visually. The perceptual perspective and appropriate affective perspective tasks were congruent with purely visual interpretations. Kurdek and Rodgon quote the findings of Maccoby and Jacklinl(1974) that spatial-verbal skill level differences between sexes is not manifest until early adolescence. However, Kurdek and Rodgon tested kindergarten through sixth grade subjects and found the sex difference in 011 grade levels. The results of the present study are drawn from a wider range of developmental levels and found the sex difference greatest at the preschool and college level with very little difference at the third grade and ninth grade level. If greater spatial variation differentiated the emotional category of stimuli from 
the benign, then perhaps preschool males and college females were attending to visual cues. What this would mean for sex differences in spatial and verbal skill development is unknown.

It could be postulated that the sex difference in favor of dependent and aggressive pictures for preschool males on the emotional/ benign contrast reflects a labeling or categorization process which differentiated the emotional pictures from the benign and resulted in more accurate perception for the preschool male subjects. Bruner (1964) discusses an "in-press study of Potter's" where children six through twelve are presented colored photographs of ordinary scenes. As they are brought gradually into focus; the six-year-olds generate many hypotheses, usually unrelated about what the picture is. The nine-yearolds also generate hypotheses but relate one to anotherg as when first perceiving a merry-go-round, their later perceptions might also relate to play equipment or amusement centers. Adolescents are even more restricted in later hypotheses to their original perceptions, even to the point of failing to accurately identify items that don't fit the scheme. Bruner cites this as evidence that children begin around age nine to both "make references to states and constraints" in their percepts not immediately evident as well as "cumulate information about them into structures which can be operated on by rules beyond similarity and contiguity." This skill is believed to increase through age 12. Perhaps the preschool male subjects' results in the present study are evidence that this ability to translate visual experience into symbolic form is present at an earlier age.

The present study seems to support Brown's (1977) contention that 
the coding flexibility of young children is underestimated. His study with four and five year olds used letter stimuli which the subjects were required to name during their initial visual presentation. He compared recall of the placement of these letters when a verbal probe (no visual cues) was used, to recall with a visual probe (no verbal. cues). The subjects had to point to where the letter was placed face down after the experimenter either showed them a letter or named the letter. The design included groups of letters with high and low visual similarity and high and low phonetic similarity. He found that there was better recall of letters of high visual similarity, even when recall was probed verbaliy. Also, when scores were uncorrected for serial position, there was a detrimental effect of high phonetic similarity in the verbal probe condition suggesting that they coded the visual items phonetically during input. It seems likely that preschoolers, like older subjects, are able to vary perceptual modality in memory tasks. In the present study, it is possible the emotional pictures represented something visually and/or phonetically to the male subjects not abstracted by the females. There are certainly more variations possible with scenes than with letters and this could by why a sex difference occurred among preschoolers in this study but none was found in Brown's work.

\section{Recognition Memory Task}

Ninth graders' recognition of dependency pictures was significantly inferior to their recognition of aggressive pictures. This result conflicts with their superior perception of dependency pictures 
on the sensory memory task. The dependent variable on the recognition memory task was the number of correct recognitions of old stimuli (yeses) plus the number of correct rejections of new stimuli (noes). Because the ninth graders' high number of errors on the recognition of dependency stimuli were produced by both more false recognitions and recognition omissions than for aggressive stimuli, an avoidance theory is not plausible as an explanation for the results. The college group had no significant difference in the number of errors on recognition of the dependent and aggressive stimuli. Even though they had more false recognitions of dependency pictures, they had less recognition omissions than they had for the aggressive category. The ninth graders seemed to have greater confusion regarding the dependency stimuli on the recognition memory task than they did for aggressive and benign stimuli: They thought they had seen the dependency pictures before when they hadn't, and they thought they hadn't seen them when in fact they had. Perhaps the intensity involved in the ninth graders' perception of the dependency photographs on the sensory memory task increased the difficulty of categorizing and associating those images on a permanent basis as Horowitz (1970) has found.

Caution must be used in linking the interpretations of the sensory and recognition memory tasks because of the different testing procedures used. The sensory memory task involved threshold level perception, a cumbersome machine, limited presentation time, and from the appearance of the subjects, a higher level of frustration. The recognition memory task involved six. new stimuli, a much more limited "yes-no" response choice, above threshold visibility, and shorter 
testing time involving less reported fatigue and frustration. Although this makes it difficult to draw comparisons between the sensory memory and recognition memory tasks, the fact remains that significant results (in opposite directions) occurred with the same population (male and female ninth graders) on the same comparison (dependent/aggressive).

The possibility of dependency photographs having relevant and salient associations that result in greater accuracy of identification on the sensory memory task has earlier been reviewed. The possibility of a broader range of associations for dependency stimuli by the ninth graders was also discussed. In a comparison of the responses from the validation of stimuli procedure done with the ninth grade and college group, there is evidence that dependency is a less discreet category for the ninth grade group. It may be that a richer associative memory process produced a heightened sensory response to the dependency stimuli but impaired storage of them. The results of the validation procedure suggest a more varied associative process involved with dependency photographs as earlier reviewed including the responses: happy, sad, caring, loving, etc. Martin (1968) discusses encoding variability and the results of research showing that high-M stimuli have less encoding variability than low-M stimuli. He worked with letter trigrams such as mop (high-M) and mqz (low-M) and found that the more finite the meaning, the greater the chance it will be perceived as a whole with the same encoding response each time it is perceived. Referring to encoding as the first stage in a two-stage process of perception, he suggests encoding is the initial information taken from the stimulus or "partial" percept." The second stage he refers to as association and is the 
response to the partial percept. If the partial percept of the same stimulus varies over time, then he hypothesizes a varied response set. The hypothesis that has been supported in a paired associate learning study is that inconsistent encoding of low-M stimuli inhibits learning or recal1. Perhaps the dependency pictures elicited one association for the ninth graders in the sensory memory task and a different association to the same pictures when presented for recognition. Furthermore, it could be hypothesized that third graders had not developed as many encoding possibilities to dependency. scenes, while college students had settled more consistentiy on one association to dependency scenes having successfully negotiated the adolescent phase. (Preschoolers' results on the second task cannot be speculated about because of the drop-out rate.)

The first introduction to the dependency stimuli. for many of the ninth graders could have been one associative level: "I don't want any child of mine looking at pornographic pictures," said when they presented the permission slip to their parents, and this may have been different from the association they made when actually presented the photographs. This broader associative field may have sensitized the ninth graders to the dependency pictures on the sensory memory task as police cadets in Toch and Schulte's (1961) were sensitized to violent scenes. This may have increased the difficulty of categorization and storage of the dependency pictures and reduced the accuracy of identification on the recognition memory task. The third grade group perhaps had a visual percept of the dependency stimuli, i.e., close - hug, which was stored at the same rate as the aggressive and benign percepts. 
If associations were generated by the dependency stimuli within the college and third grade groups, the speed of presentation may have limited their number. As indicated in the results section, conclusions cannot be drawn about the preschool group's responses on the recognition memory task because of subject loss. 


\section{SUMMARY}

The results of the study provide added support to the theories that visual perception can be qualitatively altered through the conditioning power of affective processes. In this experiment, age and sex seem to have influenced sensitivity to photographs distinguishable primarily by implied emotional content. Contrary to the working hypotheses, males do not seem to have a higher threshold for dependency scenes than for aggressive scenes, and females do not seem to have a higher threshold for aggressive scenes than for dependency scenes. The initial hypothesis that children may have coding flexibility at an earlier stage of development than previous studies suggest is supported. Further study of the processes involved in the outcome could involve preschool and third grade validation of the stimulus categories. To gain a perspective of their experience, stimulus categories could be presented to them for labeling in their language and a second group of subjects could validate or invalidate the categories. The designs of the sensory memory task and recognition memory task could be equated with the only varfable being time interval. Responses on a sensory, short-term memory task and long-term memory task could then be compared for more precise information regarding the role of these processes in the perception and storage of information from pictures with varying affective content. 


\section{REFERENCES}

Baltes, P.B., \& Nesselroade, J.R. Cultural change and adolescent personality development: An application of longitudinal sequences. Developmental Psychology, 1972, 7 (3), 244-256.

Berelson, B., \& Steiner, G.A. Human behavior: An inventory of scientific findings. Harcourt, Brace \& World, Inc., 1964.

Brecher, E.M. The sex researchers. New York: New Am. Library, 1971.

Brown, M.R. Visual and phonetic memory in preschool children:

Evidence for coding flexibility. Perceptual and Motor Skills, $1977, \underline{45}, 1043-1050$.

Bruner, J.S. The course of cognitive growth. The American Psychologist, Jan., 1964, 19, 1-15.

Bruner, J.S. \& Goodman, C.C. Value and need as organizing factors in perception. Journal of Abnormal Social Psychology, 1947, 42, 33-44.

Cantor, J.H. Individual needs and salient constructs in interpersonal perception. Journal of Personality and Social Psychology, $1976,34 .(3), 519-525$.

Conrad, R. The developmental role of vocalizing in short-term memory. Journal of Verbal Learning and Verbal Behavior, 1972, 11, 521-533.

Corteen, R.S. Skin conductance changes and word recall. British Journat of Psychology, 1969, 60 (1), 81-84.

Dixon, W.J., \& Massey F.,.Jr. Introduction to statistical analysis (3rd ed.). San Francisco: McGraw Hil1, 1968.

Feshbach, N., \& Feshbach, S. Children's aggression. In W.W. Hartup (Ed.) The young child: Reviews of research, 2, 284-302. Washington, D.C.: National Association for the Education of Young Children, 1972.

Hagen, J.H., \& Hale, G.A. The development of attention in children. In A.D. Pick (Ed), Minnesota Symposia on Child Psychology, $\underline{7}$. Minneapolis: University of Minnesota Press, 1973.

Horowitz, M.J. Image formation and cognition. New York: Meredith Corporation, 1970. 
Jenkins, N. Affective processes in perception. Psychological Bulletin, 1957, 54, 100-127.

Jersild, A. T., \& Markey, F. V. Conflicts between preschool children. Child Development Monographs, 1935, No. 21.

Jones, H. R. The use of visual and verbal memory processes by threeyear-old children. Journal of Experimental Child Psychology, $1973,15,340-351$.

Kagan, J., \& Moss, H. A. The stability of passive and dependent behavior from childhood through adul thood. Child Development, 1960,31 577-591.

Klein, G. S., Schlesinger, H. J., \& Meister,. D. E. The effect of personal values on perception: An experimental critique. Psychological Review, 1951, 58, 96-112.

$\mathrm{Kl}$ inger, $\mathrm{E}$. Consequences of commitment to and disengagement from incentives. Psychological Review, 1975, 82: (1), 1-25.

Kurdek, J. A., \& Rodgon, M. M. Perceptual, cognitive, and affective perspective taking in kindergarten through sixth grade children. Developmental Psychology, 1975, 2 (5), 643-650.

Maccoby, E. E., \& Jacklin, C. N. The psychology of sex differences. Stanford, California: Stanford University Press, 1974.

Martin, E. Stimulus meaningfulness and paired-associate transfer: an encoding variability hypothesis. Psychological Review, 1968, 75 (5), 421-441.

Odom, R. D., \& Lemond, C. M. The recall of relevant and incidental dimensional values as a function of perceptual salience, cognitive set and age. Journal of Experimental Child Psychology, 1975, 19, 524-535.

Rohwer, W. D., Jr. Images and pictures in children's learning: 'a symposium. Psychological Bulletin, 1970, 73, 393-403.

Skolnick, A. (Ed.). Rethinking childhood. Boston: Little, Brown \& Co., 1976.

Sluckin, A. M., \& Smith, P. K. Two approaches to the concept of dominance in preschool children. Child Development, 1977, 48, 917-923.

Solomon, R. L., \& Howes, D. W. Word frequency, personal values and visual deviation thresholds. Psychological Review, 1951, 58, 256-270. 
Speier, M. The adult ideological viewpoint in studies of childhood. In A. Skolnick (Ed.) Rethinking childhood. Boston: Little, Brown \& Co., 1976.

Toch, H. H., \& Schulte, R. Readiness to perceive violence as a result of police training. British Journal of Psychology, 1961, 52, (4),
389-393.

Wicklegren, W. A. Cognitive psychology. Englewood Cliffs, N. J.: 


\section{APPENDIX A \\ COLLEGE STUDENTS' QUESTIONNAIRE FOR STIMULUS VALIDATION}

The people in this photo appear to be ........

1. angry with each other 2. needing each other 3. feeling nothing in particular

The people in this photo appear to be ........

1. angry with each other 2. needing each other 3. feeling nothing in particular

The people in this photo appear to be

1. angry with each other

2. needing each other nothing in particular

The people in this photo appear to be .........

1. angry with each other 2. needing each other 3. feeling nothing in particular

The people in this photo appear to be .........

1. angry with each other

2. needing each other nothing in particular

3. feeling

The people in this photo appear to be ........

1. angry with each other

2. needing each other nothing in particular

3. feeling 
APPENDIX B

\section{NINTH GRADE STUDENTS' QUESTIONNAIRE FOR STIMULUS VALIDATION}

(A) The person or people in this photo appear to be.... .

1. angry 2. needing each other. 3. feeling nothing in particular 4. other

They are ......

1. both male 2 . both female 3 . a male and a female

(B) The person or people in this photo appear to be $\ldots . .$. .

1. angry 2. needing each other 3. feeling nothing in particular 4. other

They are ......

1. both male 2. both female 3. a male and a female

(C) The person or people in this photo appear to be .......

1. angry 2. needing each other. 3. feeling nothing in particular 4. other

They are ......

1. both male 2 . both female 3 . a male and a female

(D) The person or people in this photo appear to be .......

1. angry 2. needing each other 3. feeling nothing in particular 4. other

They are ......

1. both male 2. both female 3. a male and a female 
APPENDIX C

INITIAL CONSENT FORMS

Informed Consent

(adult)

I, hereby agree to serve, or I, hereby allow my child,

if willing, to serve as a subject in the research project involving visual perception entitled "A Study of Age and Sex-related Differences in the Perception of Emotional Stimuli" conducted by Nancy Canizio. I understand that the study involves looking at photographic pictures of adults.

It has been explained to me that the purpose of the study is to learn if there are differences in the speed with which people recognize different pictures. I may not receive any direct benefit from participating in this study, but my participation may hel.p to increase knowledge which may benefit others in the future.

I have asked and had answered to my satisfaction any questions I may have had about the study, and I understand what is expected of me or my child. I understand that I, or my child, is free to withdraw from participation in this study at any time. I have read and understand the foregoing information.

Date Signature

If you experience problems that are the result of your or your child's participation in this study, please contact Richard Streeter, Office of Graduate Studies and Research, 105 Neuberger Ha11, Portland, State University, 229-3423. 
I, am willing to participate in Nancy Canizio's research project. I understand that I am going to be looking at some photographs and will be trying to pick out which ones are shown., It has been explained to me that the purpose of the study is to find out more about how people see things. I have asked any questions I may have had. I understand I can leave the experiment at any time if I don't want to continue.

I have read, or had read to me, and understand this information. Date Signature 
APPENDIX D

\section{REVISED CONSENT FORMS}

Dear Parent(s):

I would like your child's help in completing the research work I am doing on my master's thesis at Portland State University. The staff at have agreed to let me ask for volunteers from the school to participate in my study. If you give permission and your child agrees, I would ask him/her to look at pictures through a viewer and then match them with another set.

If you would like to ask me further questions about the study before deciding whether or not to allow your child to participate, please don't hesitate to call me at 458-6029. If you are willing, please sign the enclosed form and return to your child's school.

Thank you, Nancy Canizio

Informed Consent

I, hereby agree to serve, or I, hereby allow my child,

if willing to serve as a subject in the research project involving visual perception entitled "A Study of Age and Sex-related Differences in the Perception of Emotional Stimuli" conducted by Nancy Canizio. I understand that the study involves looking at a series of pictures.

It has been explained to me that the purpose of the study is to learn if there are differences in the speed with which people recognize different pictures. I may not receive any direct benefit from 
participating in this study, but my participation may help to increase knowledge which may benefit others in the future.

I have asked and had answered to my satisfaction any questions I may have had about the study, and I, understand what is expected of me (or my child.) I understand that I, or my child, is free to withdraw from participation in this study at any time. I have read and understand the foregoing information.

Date Signature

If you experience problems that are the result of your, or your child's participation in this study, please contact Richard Streeter, Office of Graduate Studies and Research, 105 Neuberger Ha11, Portland State University, 229-3423.

\section{Informed Consent}

(minor)

I, am willing to participate in Nancy

Canizio's research project. I understand that I am going to be looking at some photographs and will be trying to pick out which ones are shown. It has been explained to me that the purpose of the study is to find out more about how people see things. I have asked any questions I may have had. I understand I can leave the experiment at any time if I don't want to continue.

I have read, or had read to me, and understand this information. Date Signature 